\title{
Stimulated mast cells promote maturation of myocardial microvascular endothelial cell neovessels by modulating the angiopoietin-Tie-2 signaling pathway
}

\author{
Z.H. Wang ${ }^{1,2}$, W. Zhu ${ }^{1}$, J.P. Tao ${ }^{1}$, Q.Y. Zhang ${ }^{1}$ and M. Wei ${ }^{1}$ \\ ${ }^{1}$ Division of Cardiology, Shanghai Sixth People's Hospital, School of Medicine, Shanghai Jiaotong University, Shanghai, China \\ ${ }^{2}$ Division of Cardiology, Yancheng People's First Hospital, Yancheng, Jiangsu, China
}

\begin{abstract}
Angiopoietin (Ang)-1 and Ang-2 interact in angiogenesis to activate the Tie-2 receptor, which may be involved in new vessel maturation and regression. Mast cells (MCs) are also involved in formation of new blood vessels and angiogenesis. The present study was designed to test whether MCs can mediate angiogenesis in myocardial microvascular endothelial cells (MMVECs). Using a rat MMVEC and MC co-culture system, we observed that Ang-1 protein levels were very low even though its mRNA levels were increased by MCs. Interestingly, MCs were able to enhance migration, proliferation, and capillary-like tube formation, which were associated with suppressed Ang-2 protein expression, but not Tie-2 expression levels. These MCs induced effects that could be reversed by either tryptase inhibitor [ $N$-tosyl-L-lysine chloromethyl ketone (TLCK)] or chymase inhibitor ( $N$-tosyl-L-phenylalanyl chloromethyl ketone), with TLCK showing greater effects. In conclusion, our data indicated that MCs can interrupt neovessel maturation via suppression of the Ang-2/Tie-2 signaling pathway.
\end{abstract}

Key words: Myocardial microvascular endothelial cells; Mast cell; Angiogenesis; Angiopoietin; Tie-2

\section{Introduction}

Recent studies showed that mast cells (MCs), a group of bone marrow-derived granulocytes, are involved in a wide range of physiological and pathological processes, including allergic reactions, and also have a role in new blood vessel induction during angiogenesis (1). These cells are topographically associated with small vessels and accumulate during angiogenesis and different pathological processes, including atherosclerosis, hemangioma, and tumor growth $(2,3)$. However, these new blood vessels display many structural and functional abnormalities, with no recognizable features of arterioles, capillaries, and venules, due to lack of normal vessel hierarchy $(4,5)$, and they are thus prone to hemorrhage.

Vascular endothelial growth factor (VEGF) and angiopoietin (Ang) are two important factors required for angiogenesis. While VEGF is required to initiate neovessel formation, Ang is needed for neovessel maturation $(6,7)$. Interestingly, studies showed an antagonistic regulation between Ang-1 and Ang-2, the two key ligands for Tie-2 receptor (known as the endothelial-specific receptor tyrosine kinase), and that they are involved in vascular formation and maturation $(8,9)$. Interrupting Ang/Tie-2 signaling has been shown to impede vascular maturation and to disrupt vessel formation. Ang- 2 has been identified as a natural antagonist of Ang-1, and it is able to inhibit Ang-1-mediated Tie-2 phosphorylation, thus interfering with angiogenesis. Therefore, Ang-2 has been identified as a vessel-destabilizing agent that plays a predominant role in controlling vesse regression (10). Importantly, in the absence of VEGF increased Ang-2 levels lead to endothelial cell apoptosis, immature neovessel destabilization, and neovessel regression (11). Thus, VEGF not only acts as a stimulator for initial vessel formation, but also promotes neovessel maturation by modulating the Ang-Tie-2 signaling pathway.

Recent studies showed that MCs are the main source of circulating VEGF released by degranulation (12). MCderived Ang-1 can promote the growth of plasmacytomas by stimulating neovascularization (13). These studies

Correspondence: Q.Y. Zhang and/or M. Wei, Division of Cardiology, Shanghai Sixth People's Hospital, School of Medicine, Shanghai Jiaotong University, State Key Discipline Division, No. 600 Yishan Road, Shanghai 200223, China. Fax: +86-21-6436-9181. E-mail: yeakcardio@yahoo.com.cn (Q.Y.Z.) and/or weim.sjtu6h@hotmail.com (M.W.) 
indicated that MCs provide sufficient VEGF to promote the angiogenesis process. However, there is a lack of data showing whether MCs also affect the Ang-Tie-2 system in microvascular endothelial cells. We hypothesized that those disorders in Ang-Tie-2 signaling cause immature and incomplete $\mathrm{MC}$-induced neovessel formation. In the present study, we co-cultured myocardial microvascular endothelial cells (MMVECs) with MCs to study 1) whether MC granules (MCGs) can promote angiogenesis in MMVECs, 2) how tryptase and chymase play a role in modulating MC-induced neovessel maturation, and 3) whether co-culturing MMVECs with MCs leads to stimulation of Ang-Tie-2 signaling.

\section{Material and Methods}

\section{Reagents}

All cell culture reagents, AlamarBlue ${ }^{\circledR}$ cell viability reagent, Trizol reagent, the SuperScript ${ }^{\mathrm{TM}}$ III First-Strand Synthesis System for RT-PCR, and Platinum SYBR Green qPCR SuperMix were purchased from Invitrogen Life Technologies Inc. (USA). Primary antibodies against Ang-1, Ang-2, Tie-2, and $\beta$-actin, as well as secondary antibodies against either rabbit or mouse IgG were purchased from Santa Cruz Biotechnology, Inc. (USA). Super Signal West Pico chemiluminescent substrate was obtained from Pierce Biotechnology, Inc. (USA). All other reagents were from Sigma (USA).

\section{MMVEC culture}

Primary MMVECS were obtained from Wistar rats (80$100 \mathrm{~g}$ ). The experimental protocol was approved by the Ethics Committee of Shanghai Jiaotong University (approval ID: SYXK2009-0152). MMVECs were isolated as previously described (14). Rats were anesthetized with sodium pentobarbital $(60 \mathrm{mg} / \mathrm{kg})$ and injected with heparin. After thoracotomy, the heart was rapidly removed and washed in PBS. The atria, visible connective tissue, valvular tissue, right ventricle, and epicardial and endocardial surfaces of the left ventricle were carefully removed. The remaining myocardial tissue was cut into $1-\mathrm{mm}^{3}$ pieces without visible vessels. Myocardial tissues were seeded on culture plates precoated with rat-tail tendon gelatin and incubated at $37^{\circ} \mathrm{C}$ in a humidified atmosphere (5\% CO $\mathrm{CO}_{2}-95 \%$ air). After a 30-min attachment period, tissues were cultured in DMEM $(4500 \mathrm{mg} / \mathrm{L}$ Dglucose) supplemented with $20 \%$ fetal bovine serum (FBS), $50 \mathrm{U} / \mathrm{mL}$ heparin, $100 \mathrm{U} / \mathrm{mL}$ penicillin, and $100 \mu \mathrm{g} / \mathrm{mL}$ streptomycin. Tissue pieces were discarded and the medium was changed after $70 \mathrm{~h}$. MMVECs were identified by their typical "cobblestone" appearance and positive CD31 and CD34 staining by immunocytochemistry. MMVECs were used at second passage for the following experiments. Cells were allowed to grow to $80-90 \%$ confluence and were serum starved for $24 \mathrm{~h}$ before experiments.

\section{Collection and isolation of MCs}

MCs were isolated as previously described (15), with minor modifications. Briefly, MCs from peritoneal cavities of Wistar rats (200-250 g) were collected by washing with 15 mL RPMI 1640 (supplemented with 1\% FBS). After a 1-h attachment period in the incubator, nonadherent cells, mainly MCs, were separated using Percoll density gradient centrifugation at $2500 \mathrm{~g}$ for $15 \mathrm{~min}$ at $4{ }^{\circ} \mathrm{C}$, and cells that remained at the Percoll interface were aspirated and resuspended in PBS. MCs were washed twice in PBS and cultured in RPMI 1640, supplemented with 10\% FBS, $25 \mathrm{mM}$ HEPES, $100 \mathrm{U} / \mathrm{mL}$ penicillin, and $100 \mathrm{mg} / \mathrm{mL}$ streptomycin. MCs isolated by this procedure exceeded $90 \%$ purity based on staining with $0.05 \%$ toluidine blue $\mathrm{O}$.

\section{Preparation of MCGs}

Standard incubation was conducted in $200 \mu \mathrm{L}$ RPMl 1640 containing $5.0 \times 10^{6}$ cells $/ \mathrm{mL}$ MCs. After preincubation at $37^{\circ} \mathrm{C}$ for $15 \mathrm{~min}, \mathrm{MCs}$ were stimulated to degranulate with compound $48 / 80(5 \mu \mathrm{g} / \mathrm{mL})$, a noncytotoxic, MC-specific stimulator, and incubation was continued for $1 \mathrm{~min}$. After stimulation, cells were sedimented by centrifugation at $800 \mathrm{~g}$ for $5 \mathrm{~min}$. The supernatant containing all the material released from the stimulated MCs was stored at $-80^{\circ} \mathrm{C}$ and used for further experiments (16). Tryptase and chymase enzyme activity in the MCG preparation was measured as described previously (17). Tryptase activity was determined by its ability to cleave $2 \mathrm{mM} \mathrm{L}$-arginine- $p$-nitroanilide in $0.1 \mathrm{M}$ Tris- $\mathrm{HCl}$, $\mathrm{pH} 8.0$, and $1 \mathrm{mM}$ glycerol, and was read at $410 \mathrm{~nm}$. Chymase activity was determined spectrophotometrically by the rate of hydrolysis of $0.7 \mathrm{mM} \mathrm{N}$-succinyl-Lphenylalanine- $p$-nitroanilide in $1.5 \mathrm{mM} \mathrm{NaCl}$ and $0.3 \mathrm{mM}$ Tris, $\mathrm{pH} 8.0$, and was read at $405 \mathrm{~nm}$. Protease activity was reported as $\mathrm{mU} / \mathrm{mL}$, in which $1 \mathrm{U}$ enzyme activity was defined as the amount degrading $1 \mu \mathrm{mol}$ substrate/min at $25^{\circ} \mathrm{C}$. Tryptase activity of MCG preparations used in the present study was $9.46 \mathrm{mU} / \mathrm{mL}$, and chymase activity was $3.57 \mathrm{mU} / \mathrm{mL}$.

\section{MMVEC-MC co-culture}

MMVECs $\left(1 \times 10^{5}\right.$ cells/well $)$ and MCs $\left(1 \times 10^{5}\right.$ cells/ well) were co-cultured in DMEM as described previously in the presence or absence of compound 48/80 (5 $\mu \mathrm{g} / \mathrm{mL})$ for $8 \mathrm{~h}$ (18). MMVECs were further incubated with MCGs for $8 \mathrm{~h}$ at $37^{\circ} \mathrm{C}$ in humidified $95 \%$ air- $5 \% \mathrm{CO}_{2}$. Confluent MMVECs were washed with PBS, removed by trypsinization, and seeded onto 6-well culture plates in DMEM $\left(1 \times 10^{5}\right.$ cells/well). MCG quantities corresponding to $5 \times 10^{3}, 2.5 \times 10^{4}$, and $1 \times 10^{5} \mathrm{MCs}$ were added to the wells. Cells were incubated at $37^{\circ} \mathrm{C}$ in humidified $95 \%$ air$5 \% \mathrm{CO}_{2}$ for an additional $8 \mathrm{~h}$. MMVECs were washed twice with ice-cold PBS, followed by isolation of total RNA.

MMVECs were seeded on a plate and grown to near confluence before being quiesced in DMEM with $1 \%$ FBS for $24 \mathrm{~h}$. They were then treated with MCGs, N-tosyl-L-lysine 
chloromethyl ketone (TLCK), and N-tosyl-L-phenylalanyl chloromethyl ketone (TPCK), and were used for further experiments.

\section{Cell proliferation assay}

Cell proliferation was assessed by cell counting after staining with AlamarBlue ${ }^{\circledR}$ cell viability reagent. MMVECs were seeded onto 96-well cell culture plates at an initial density of $5 \times 10^{3}$ cells/well $(100 \mu \mathrm{L})$ in DMEM with $5 \%$ FBS in the presence or absence of MCGs, TLCK, and TPCK. After an overnight incubation, $10 \mu \mathrm{L}$ AlamarBlue ${ }^{\mathbb{R}}$ solution was added and incubated for an additional $2 \mathrm{~h}$. Data were obtained by measuring cell growth for 5 consecutive days with a microplate reader (Tecan Group Ltd., Switzerland) at 570 and $600 \mathrm{~nm}$. A cell proliferation curve was obtained using absorbance at $570 \mathrm{~nm}$ subtracted from absorbance at $600 \mathrm{~nm}$.

\section{Cell migration assay}

Cell migration was assessed using Transwell inserts precoated with fibronectin. Inserts were placed on a 24-well plate containing $800 \mu \mathrm{L}$ DMEM and $2 \%$ FBS in the presence or absence of MCGs, TLCK, and TPCK. MMVECs were trypsinized, harvested, and added to the upper chamber of the inserts in $200 \mu \mathrm{L}$ serum-free DMEM $\left(4 \times 10^{4}\right.$ cells/well). Cells were allowed to migrate from the upper to the lower chamber for $12 \mathrm{~h}$ at $37^{\circ} \mathrm{C}$. The cells that remained in the upper chamber were scraped off by wiping with a swab tip. Cells that migrated to the lower side of the Transwell inserts were fixed with methanol for 10 min and stained with crystal violet dye. After PBS washing to remove excess crystal violet dye, cells on the lower side of the insert membrane were counted in 5 random fields (200X).

\section{Cell scratch wound healing assay}

Wound healing assay was performed as previously reported (19). When MMVECs became confluent on 24well plates, a wound was made with a $200-\mu \mathrm{L}$ pipette tip. Cells were washed with PBS and further incubated in DMEM with $1 \%$ FBS in the presence or absence of MCGs, TLCK, and TPCK. After $24 \mathrm{~h}$ of incubation, migration was photographed and quantified using the Image J software version 1.37 (National Institutes of Health, USA) by measuring the proportion of cells that moved beyond the reference line.

\section{Capillary-like tube formation assay on Matrigel}

After trypsinization, cells were seeded on Matrigel (BD Biosciences, USA). Briefly, $100 \mu \mathrm{L} /$ well of this matrix solution was added to a 24-well culture plate. After solidification at $37^{\circ} \mathrm{C}$ for $30 \mathrm{~min}$, MMVECs resuspended in DMEM with $1 \%$ FBS in the presence or absence of MCGs, TLCK, and TPCK were added onto the surface of the Matrigel $\left(5 \times 10^{4}\right.$ cells/well) and incubated for $18 \mathrm{~h}$ at $37^{\circ} \mathrm{C}$. Tube formation was observed and images were captured. Structures were quantified by counting all branches in three random fields from each well (20). Each experiment was repeated three times.

\section{Real-time reverse-transcription PCR}

Total RNA was extracted from MMVECs using Trizol reagent, according to the manufacturer's protocol. RNA $(2 \mu \mathrm{g})$ was then reverse-transcribed into cDNA using the SuperScript $^{\mathrm{TM}}$ III First-Strand Synthesis System RT-PCR kit and was further amplified using SYBR Green RT-PCR with the following specific oligonucleotides: Ang-1 sense primer, 5'-CAG CAC AAA GGA CGC TGA TA-3' and antisense primer, 5'-ATA GCG CCT TCA GAA GTC CA3'; Ang-2 sense primer, 5'-GAT CTT GTC TTG GCC TCA GC-3' and antisense primer, 5'-ACG GCG TTA GAC ATG TAG GG-3'; Tie-2 sense primer, 5'-AGG GCC TAG AGC CAG AGA CT-3' and antisense primer, 5'-AAG GTC TTT AGG GGC TGG AA-3'; or $\beta$-actin sense primer, 5'-CAC CCG CGA GTA CAA CCT TC-3' and antisense primer, 5'-CCC ATA CCC ACC ATC ACA CC-3'. The SYBR Green RT-PCR amplification was carried out in a $25-\mu \mathrm{L}$ reaction volume that contained $12.5 \mu \mathrm{L} 2 \mathrm{X}$ Platinum SYBR Green qPCR SuperMix, $200 \mathrm{nM}$ each of the forward and reverse primers, and $2 \mu \mathrm{L}$ of diluted cDNA using the iCycler $\mathrm{iQ}^{\mathrm{TM}}$ Real-Time PCR Detection System (Bio-Rad, USA). Each sample was performed in triplicate. The measurement was repeated four times to ensure reliability of results. RT-PCR was conducted for 40 cycles under the following conditions: denaturation at $94^{\circ} \mathrm{C}$ for $30 \mathrm{~s}$, annealing at optimal temperature for each primer pair for $30 \mathrm{~s}$, and extension at $72^{\circ} \mathrm{C}$ for $45 \mathrm{~s}$. Final extension was performed at $72^{\circ} \mathrm{C}$ for $10 \mathrm{~min}$. A single amplification product was confirmed by running a melting curve for all PCRs. The relative expression levels of the target gene mRNA were analyzed according to the kit instructions. Ct value was defined as the number of cycles for the fluorescent intensity of the amplified products to reach the detection threshold. ${ }^{\Delta} \mathrm{Ct}$ was calculated by subtracting the $\beta$-actin $\mathrm{Ct}$ value from the target gene $\mathrm{Ct}$ value. ${ }^{\Delta \Delta} \mathrm{Ct}$ was the difference between ${ }^{\Delta} \mathrm{Ct}$ values of the experimental group and the control group. The time to reach the mRNA expression levels in the experimental groups compared with the control group was $2^{-\Delta \Delta C t}$.

\section{Western blot for Ang-1, Ang-2, and Tie-2}

MMVECs were lysed in lysis buffer (Beyotime, China) and protein content was measured using the BCA assay (Beyotime). The amount of protein loaded per well was $50 \mu \mathrm{g}$ and these proteins were separated on an $8-12 \%$ Tris-glycine gel and transferred to a PVDF membrane. Primary antibodies against Ang-1 (1:200 dilution), Ang-2 (1:500 dilution), Tie-2 (1:500 dilution), and $\beta$-actin (1:500 dilution) were added and incubated overnight at $4{ }^{\circ} \mathrm{C}$, followed by reacting with the appropriate secondary antibody (1:4000 dilution, goat anti-rabbit lgG, and goat anti-mouse lgG-HRP) for $2 \mathrm{~h}$. Electrochemiluminescence reagent was then used to determine the immunoreaction 
and was measured by densitometry on an X-ray film, using the GIS software (Bio-Tanon, China). All Western blot experiments were repeated at least three times with different cell preparations.

\section{Statistical analysis}

Data are reported as means \pm SE. Statistical significance was assessed by one-way ANOVA followed by post hoc analysis using the Student-Newman-Keuls test. $\mathrm{P}<0.05$ was considered to be statistically significant. Statistical analyses were performed using SPSS 16.0 (IBM Corp., USA).

\section{Results}

\section{Effect of MCs on Ang-1 mRNA expression in MMVECs}

Ang-1 mRNA levels in MMVECs increased significantly by 2.2-fold in MMVECs co-cultured with MCs that were previously stimulated with compound 48/80, compared with MMVECs without any treatment $(P<0.01$; Figure 1A). In contrast, co-culture of MMVECs with nonactivated MCs resulted in a trend to increased Ang-1 mRNA levels (Figure 1A), which could be due to the slow process of spontaneous degranulation in MCs without any stimulation. The addition of compound $48 / 80$ alone, without MCs, did not have any significant effect on Ang-1 mRNA levels (Figure 1A).

In another set of experiments, MCGs obtained from different amounts of stimulated MCs $\left(5 \times 10^{3}, 2.5 \times 10^{4}\right.$, and $1 \times 10^{5}$ ) were added to $1 \times 10^{5}$ MMVECs and were then incubated for $8 \mathrm{~h}$. Ang-1 mRNA levels showed a dose-response relationship $(\mathrm{P}<0.01$; Figure $1 \mathrm{~B})$.

\section{Angiogenesis changes under different conditions in vitro}

Our results showed that MCGs promoted MMVEC growth with a significantly higher proliferation rate than for MMVECs without MCGs $(P<0.05)$. However, these
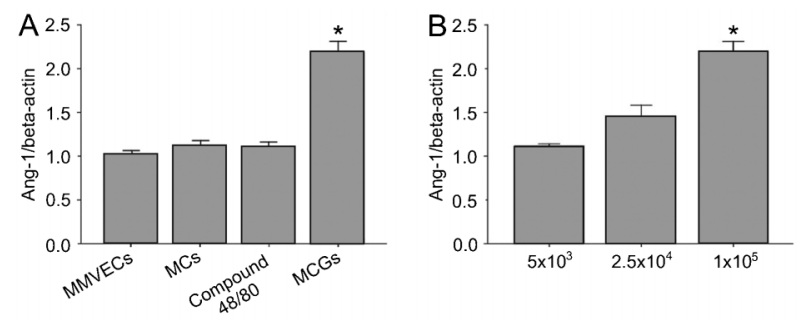

Figure 1. Effect of MCs activation on Ang-1 mRNA levels in coculture of MMVECs. A, MMVECs were cultured with nonactivated MCs, compound $48 / 80$ and activated MCs. $B$, MCGs corresponding to $5 \times 10^{3}, 2.5 \times 10^{4}$, and $1 \times 10^{5} \mathrm{MCs}$ were added to MMVECs. Data are reported as means $\pm S E(n=3)$. MCs: mast cells; Ang-1: angiopoietin; MMVECs: myocardial microvascular endothelial cells; MCGs: MC granules. ${ }^{*} \mathrm{P}<0.05$, StudentNewman-Keuls test. effects were totally abolished when TLCK or TPCK was added, resulting in an even lower proliferation rate than in MMVECs alone $(P<0.05$; Figure $2 A)$.

Cell migration, as measured using Transwell and cell scratch wound healing assays, was significantly improved in MMVECs co-cultured with MCGs compared with those without treatment $(\mathrm{P}<0.05$; Figure $2 \mathrm{~B}$ and $\mathrm{C})$. Matrigel assay indicated more capillary-like tube formation by MMVECs in the presence of MCGs $(P<0.05$; Figure 2B and $\mathrm{C}$ ). More importantly, the effects of MCGs were significantly suppressed by adding TLCK and TPCK, resulting in an even lower migration and capillary-like tube formation than in MMVECs alone $(\mathrm{P}<0.05$; Figure 2B and C), and TLCK almost completely abolished capillary-like tube formation ability of MMVECs.

\section{Effects of MCGs and inhibitors on Ang and Tie-2 mRNA expression in MMVECs}

Ang-2 mRNA expression showed an increase in time in MMVECs, with a peak at $8 \mathrm{~h}$, followed by a trend to decrease since $16 \mathrm{~h}$. MCGs, however, resulted in lower Ang-2 mRNA expression in MMVECs at each time point after being co-cultured for $8 \mathrm{~h}(\mathrm{P}<0.05$, vs $2 \mathrm{~h}$; Figure 3B). In contrast, Ang-1 mRNA expression was unchanged with time in MMVECs $(P>0.05$; Figure $3 A)$, MCGs enhanced its expression, but only at $8 \mathrm{~h}(\mathrm{P}<0.05$, vs $2 \mathrm{~h}$; Figure 3A). Interestingly, Tie-2 mRNA was not affected by MCGs (Figure $3 \mathrm{C}$ ). Both TLCK and TPCK abolished the effects of MCGs on Ang-1 and Ang-2 mRNA expression, without affecting Tie-2 mRNA expression (Figure 3D-F).

\section{Ang-1, Ang-2, and Tie-2 protein expression}

The time course of changes in Ang-1, Ang-2, and Tie-2 expression was assessed, showing an increase in time in Ang-2 expression, with a peak at $24 \mathrm{~h}$ of culture. Both Ang-1 and Tie-2 demonstrated low expression levels, with Ang-1 being undetectable in MMVECs. MMVECs co-cultured with MCGs exhibited a similar pattern of changes compared with MMVECs alone. Ang-2 expression was quantified after $24 \mathrm{~h}$ of culture, demonstrating a suppressive effect of MCGs on Ang-2 expression $(P<0.05$; Figure $4 A, C)$. This suppressive effect was removed by adding either TLCK or TPCK $(P<0.05$; Figure 4B,D), with a higher expression than in MMVECs alone when TLCK was added $(P<0.05$; Figure 4B,D).

\section{Discussion}

Angiogenesis requires a number of coordinated signaling events from a variety of angiogenic factors and their receptors. Ang-1 and Ang-2, the two key ligands for the Tie-2 receptor, play interactive roles in angiogenesis. While Ang- 1 can activate Tie-2, Ang-2 has a similar affinity for Tie-2, but does not activate it, and competes with Ang-1 for Tie-2 binding. It has been shown that Ang-1 

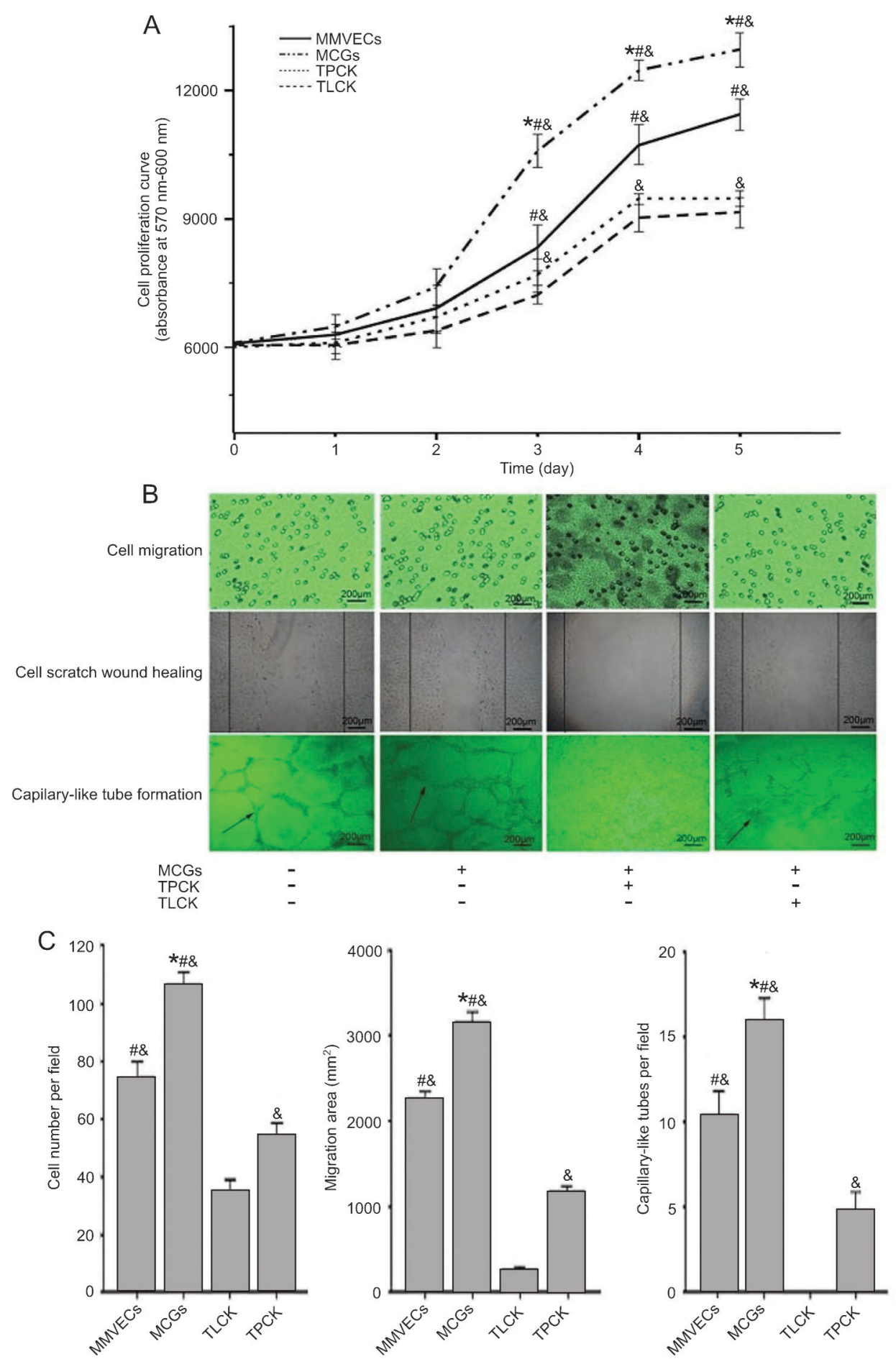

Figure 2. Angiogenesis changes in different conditions in vitro. A, Cell proliferation curve was obtained by AlamarBlue ${ }^{\circledR}$ cell viability reagent. $B, C$, Representative images of migration across Transwell membrane, scratch wound healing and capillary-like tube formation were captured and counted under a contrast phase microscope. Data are reported as means $\pm S E(n=3)$. MMVECs: myocardial microvascular endothelial cells; MCGs: mast cell granules; TLCK: $N$-tosyl-L-lysine chloromethyl ketone; TPCK: N-tosyl-L-phenylalanyl chloromethyl ketone. ${ }^{*} \mathrm{P}<0.05$ vs MMVECs, ${ }^{\&} \mathrm{P}<0.05$ vs TLCK, ${ }^{\#} \mathrm{P}<0.05$ vs TPCK (Student-Newman-Keuls test). 

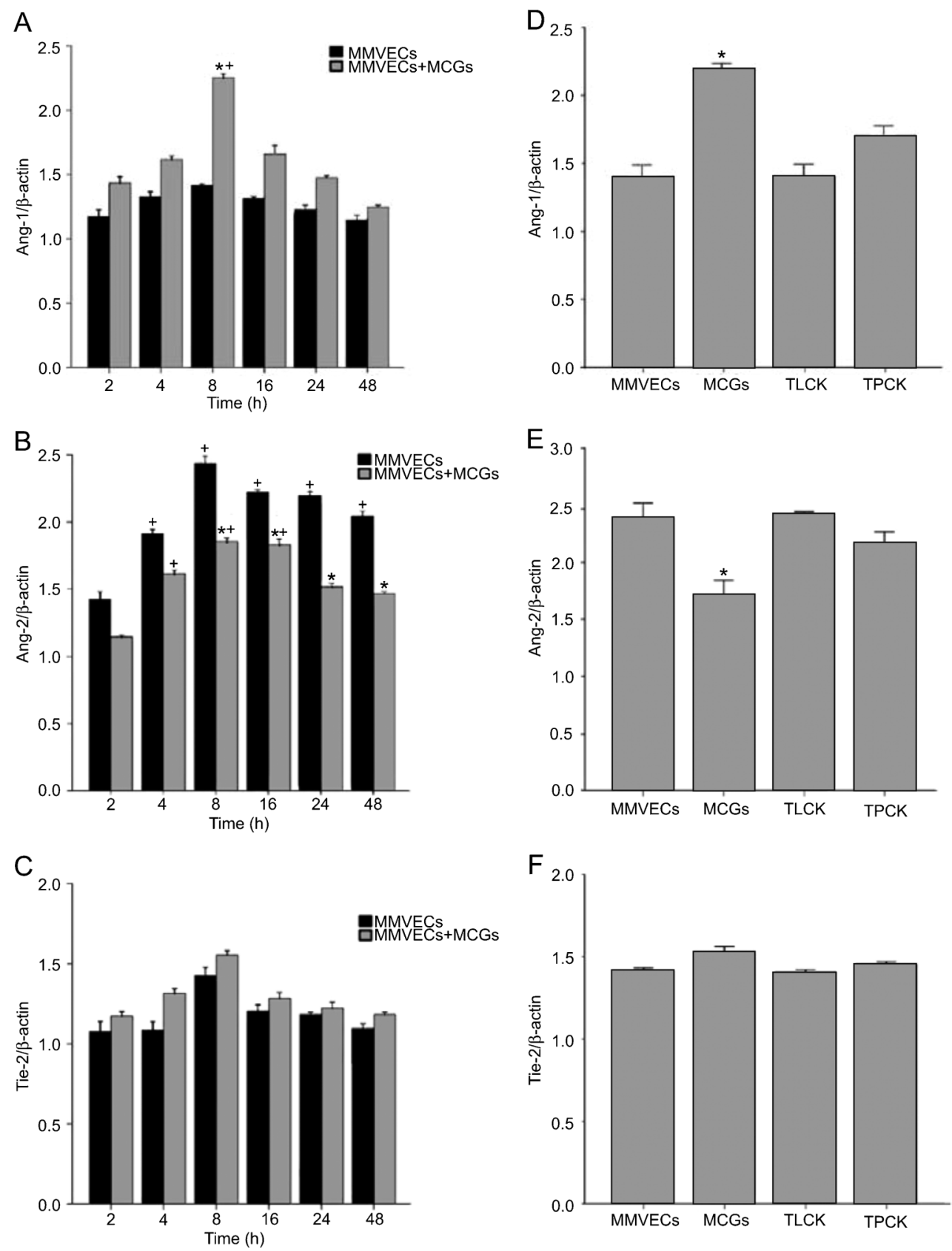

Figure 3. Ang-1, Ang-2 and Tie-2 mRNA expression in MMVECs. A, Ang-1 increased significantly in MMVECs with MCGs at 8 h. $B$, Ang-2 decreased significantly in MMVEC with MCGs compared to MMVECs from $8 \mathrm{~h}$. $C$, Tie-2 mRNA was not affected by MCGs. $D-F$, Both TLCK and TPCK abolished the effects of MCGs on Ang-1 and Ang-2 mRNA expression, without affecting Tie-2 mRNA expression. Ang: angiopoietin; MMVECs: myocardial microvascular endothelial cells; MCGs: mast cell granules; TLCK: N-tosyl-L-lysine chloromethyl ketone; TPCK: $N$-tosyl-L-phenylalanyl-chloromethyl ketone. ${ }^{*} \mathrm{P}<0.05$ vs MMVECs, ${ }^{+} \mathrm{P}<0.05$ vs 2 h (Student-NewmanKeuls test).

is an agonist for endothelial cells and that Ang-2 can act as a context-dependent antagonist (21). Studies demonstrated that Ang-1 is essential for vascular development by promoting blood vessel maturation (9), and by inhibiting vessel leakage, endothelial apoptosis, and microvascular regression (22). Consistent with these in vivo studies, Ang-1 promotes monolayer integrity in cultured endothelial cells (23). In contrast, Ang-2 has been identified 

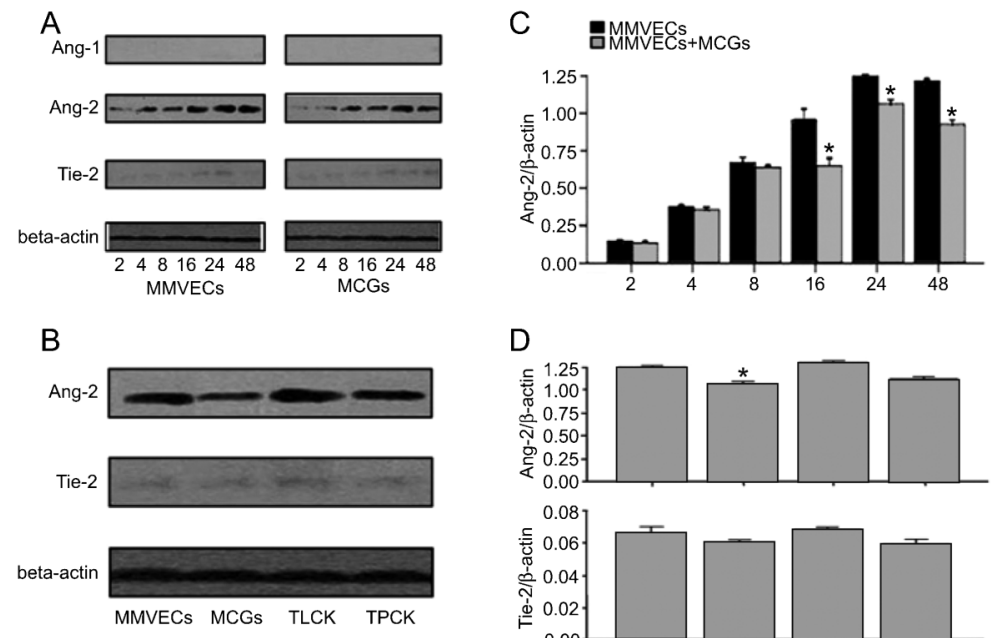

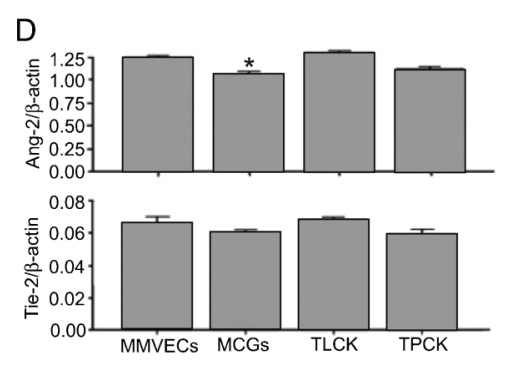

Figure 4. Ang-1, Ang-2 and Tie-2 protein expression in MMVECs. $A, C$, Tie-2 had no obvious change. Ang-1 was not expressed in MMVECs. Ang-2 decreased significantly in MMVEC with MCGs compared to MMVECs from $16 \mathrm{~h}$ ( ${ }^{*} \mathrm{P}<0.05$, Student-Newman-Keuls test). $B, D$, Expression of Ang-2 increased in the presence of TLCK or TPCK, especially of TLCK. Ang: angiopoietin; MMVECs: myocardial microvascular endothelial cells; MCGs: mast cell granules; TLCK: N-tosyl-L-lysine chloromethyl ketone; TPCK: N-tosyl-L-phenylalanyl chloromethyl ketone. ${ }^{*} \mathrm{P}<0.05$ vs MMVECs (StudentNewman-Keuls test). as a natural antagonist of Ang-1 and can inhibit Ang-1mediated Tie-2 phosphorylation and angiogenesis (10). Ang-2 has been recognized as a vessel-destabilizing agent playing a predominant role in controlling vessel regression.

In our study, using an MMVEC and MC co-culture system, we observed that active MCs could promote in vitro angiogenesis by MMVECs, which was not observed with nonactivated MCs. However, the new blood vessels induced by MCs display many structural and functional abnormalities $(4,5)$. Paradoxically, enhanced migration, proliferation, and capillary-like tube formation of MMVECs induced by MCGs also show an interrupted vessel maturation process. Importantly, these changes in angiogenesis were associated with a decreased Ang-2 expression. Interestingly, although MCGs increased Ang-1 mRNA expression, the Ang-1 protein was not detected in this coculture system, which was also observed by another group (24). This could be related to the different species or different tissue that we used $(25,26)$. Nevertheless, our results clearly showed that MCGs decreased the Ang-2/ Tie-2 signaling pathway.

Classically, MCs are divided into two types depending upon the expression of different proteases in their granules (27). $\mathrm{MC}_{\mathrm{T}}$ cells containing mainly tryptase are predominantly located in the respiratory and intestinal mucosa, while $\mathrm{MC}_{\mathrm{TC}}$ cells, expressing both tryptase and chymase, are predominantly found in connective tissues of skin, conjunctiva, and synovia $(28,29)$. Tryptase and chymase are the predominant proteases present in MCGs. Tryptase constitutes more than $20 \%$ of the MC protein on a weight basis, with 10-35 pg tryptase per cell (30). Chymase is a serine protease with chymotrypsin-like substrate specificity and is one of the major components of MCGs (31). Previous studies showed that tryptase and chymase are angiogenic factors $(32,33)$. However, there is a lack of data regarding which protease is more important in the angiogenesis process. In our study, we confirmed that both tryptase and chymase are present in MCs obtained from rat peritoneal cavities (data not shown). Using specific tryptase and chymase inhibitors, we tested the effects of these factors on angiogenesis. Migration, proliferation, and capillary-like tube formation of MMVECs were significantly suppressed by either TLCK or TPCK, with TLCK showing the stronger effects. The same phenomenon was observed when suppressing Ang-2 expression in MMVECs by MCGs, which could be recovered by adding either TLCK or TPCK, resulting in even higher expression than with MMVECs alone when TLCK was added. Thus, our data clearly indicate that tryptase may be more important than chymase in angiogenesis. However, we could not fully explain why TLCK or TPCK resulted in even less migration, proliferation, and capillary-like tube formation than in MMVEC controls. This could be due to the fact that, in the setting of inhibition of the main angiogenic factors of MCGs (tryptase or chymase), other antiangiogenic factors are secreted, such as endothelin-1, which could in turn suppress angiogenesis (34).

Our present study mainly focused on angiogenesis in MMVECs in vitro, co-cultured with MCs. However, other cells, such as smooth muscle cells, also participate in the angiogenic process. In vivo angiogenesis is complex and can be affected by many factors. Nevertheless, using a co-culture system, we clearly showed that MCGs can suppress Ang-2/Tie-2 signaling and interrupt neovessel maturation. However, it is still unclear whether MCGs can regulate the phosphorylation of Ang-2/Tie-2.

Our results demonstrate that MCGs, but not nonactivated $\mathrm{MCs}$, increased proliferation, migration, and capillary-like tube formation in MMVECs. This was suppressed by either TLCK or TPCK, with TLCK showing stronger effects, suggesting that tryptase was 
the major factor promoting neovessels in MCs. These effects were associated with a disrupted Ang-2/Tie-2 signaling pathway, thus indicating an important role for MCs cooperating with MMVECs in the neovessel maturation process.

\section{References}

1. Leslie M. Mast cells show their might. Science 2007; 317: 614-616, doi: 10.1126/science.317.5838.614.

2. Wang Y, Shi GP. Mast cell chymase and tryptase in abdominal aortic aneurysm formation. Trends Cardiovasc Med 2012; 22: 150-155, doi: 10.1016/j.tcm.2012.07.012.

3. Bialas M, Dyduch G, Szpor J, Demczuk S, Okon K. Microvascular density and mast cells in benign and malignant pheochromocytomas. Pol J Pathol 2012; 63: 235-242, doi: 10.5114/pjp.2012.32770.

4. Ribatti D, Nico B, Crivellato E, Vacca A. The structure of the vascular network of tumors. Cancer Lett 2007; 248: 18-23, doi: 10.1016/j.canlet.2006.06.007.

5. Bot I, de Jager SC, Zernecke A, Lindstedt KA, van Berkel TJ, Weber $\mathrm{C}$, et al. Perivascular mast cells promote atherogenesis and induce plaque destabilization in apolipoprotein E-deficient mice. Circulation 2007; 115: 2516-2525, doi: 10.1161/CIRCULATIONAHA.106.660472.

6. Danza K, Pilato B, Lacalamita R, Addati T, Giotta F, Bruno $\mathrm{A}$, et al. Angiogenetic axis angiopoietins/Tie2 and VEGF in familial breast cancer. Eur J Hum Genet 2013; 21: 824-830, doi: 10.1038/ejhg.2012.273.

7. Huang S, Yang N, Liu Y, Hu L, Zhao J, Gao J, et al. Grape seed proanthocyanidins inhibit angiogenesis via the downregulation of both vascular endothelial growth factor and angiopoietin signaling. Nutr Res 2012; 32: 530-536, doi: 10.1016/j.nutres.2012.05.012.

8. Staton CA, Valluru M, Hoh L, Reed MW, Brown NJ. Angiopoietin-1, angiopoietin-2 and Tie-2 receptor expression in human dermal wound repair and scarring. $\mathrm{Br} J$ Dermatol 2010; 163: 920-927, doi: 10.1111/j.1365-2133. 2010.09940.x.

9. Girling JE, Rogers PA. Regulation of endometrial vascular remodelling: role of the vascular endothelial growth factor family and the angiopoietin-TIE signalling system. Reproduction 2009; 138: 883-893, doi: 10.1530/REP-09-0147.

10. Felcht M, Luck R, Schering A, Seidel P, Srivastava K, Hu J, et al. Angiopoietin-2 differentially regulates angiogenesis through TIE2 and integrin signaling. J Clin Invest 2012; 122: 1991-2005, doi: 10.1172/JCI58832.

11. Lobov IB, Brooks PC, Lang RA. Angiopoietin-2 displays VEGF-dependent modulation of capillary structure and endothelial cell survival in vivo. Proc Natl Acad Sci U S A 2002; 99: 11205-11210, doi: 10.1073/pnas.172161899.

12. Patruno R, Arpaia N, Gadaleta CD, Passantino L, Zizzo N, Misino A, et al. VEGF concentration from plasma-activated platelets rich correlates with microvascular density and grading in canine mast cell tumour spontaneous model. J Cell Mol Med 2009; 13: 555-561, doi: 10.1111/j.1582-4934. 2008.00355.x.

13. Nakayama T, Yao L, Tosato G. Mast cell-derived

\section{Acknowledgments}

Research supported by an Institutional Research Grant (to M. Wei) and the Shanghai PuJiang Program (\#PJ[2008]00586 to Q.Y. Zhang). angiopoietin-1 plays a critical role in the growth of plasma cell tumors. J Clin Invest 2004; 114: 1317-1325.

14. Ning $Y$, Wang $X$, Jin H, Zhao F, Yin L. Study on the culture of rat myocardium microvascular endothelial cells and microarray analysis. Chin J Pathophysiol 2005; 21: 2295.

15. Kokkonen JO, Kovanen PT. Low density lipoprotein degradation by rat mast cells. Demonstration of extracellular proteolysis caused by mast cell granules. J Biol Chem 1985; 260: 14756-14763.

16. Kokkonen JO, Kovanen PT. Accumulation of low density lipoproteins in stimulated rat serosal mast cells during recovery from degranulation. J Lipid Res 1989; 30: 1341-1348.

17. He S, Peng Q, Walls AF. Potent induction of a neutrophil and eosinophil-rich infiltrate in vivo by human mast cell tryptase: selective enhancement of eosinophil recruitment by histamine. J Immunol 1997; 159: 6216-6225.

18. Wang $\mathrm{XH}$, Chen SF, Jin HM, Hu RM. Differential analyses of angiogenesis and expression of growth factors in microand macrovascular endothelial cells of type 2 diabetic rats. Life Sci 2009; 84: 240-249, doi: 10.1016/j.Ifs.2008.12.010.

19. Ettenson DS, Gotlieb Al. Centrosomes, microtubules, and microfilaments in the reendothelialization and remodeling of double-sided in vitro wounds. Lab Invest 1992; 66: 722-733.

20. Pollman MJ, Naumovski L, Gibbons GH. Endothelial cell apoptosis in capillary network remodeling. J Cell Physiol 1999; 178: 359-370, doi: 10.1002/(SICI)10974652(199903)178:3<359::AID-JCP10>3.0.CO;2-O.

21. Fagiani $E$, Lorentz $P$, Kopfstein L, Christofori G. Angiopoietin1 and -2 exert antagonistic functions in tumor angiogenesis, yet both induce lymphangiogenesis. Cancer Res 2011; 71: 5717-5727, doi: 10.1158/0008-5472.CAN-10-4635.

22. Nambu H, Nambu R, Oshima $Y$, Hackett SF, Okoye G, Wiegand S, et al. Angiopoietin 1 inhibits ocular neovascularization and breakdown of the blood-retinal barrier. Gene Ther 2004; 11: 865-873, doi: 10.1038/sj.gt.3302230.

23. Satchell SC, Anderson KL, Mathieson PW. Angiopoietin 1 and vascular endothelial growth factor modulate human glomerular endothelial cell barrier properties. J Am Soc Nephrol 2004; 15: 566-574, doi: 10.1097/01.ASN.0000115397.22519.03.

24. Chlench S, Mecha Disassa N, Hohberg M, Hoffmann C, Pohlkamp T, Beyer G, et al. Regulation of Foxo-1 and the angiopoietin-2/Tie2 system by shear stress. FEBS Lett 2007; 581: 673-680, doi: 10.1016/j.febslet.2007.01.028.

25. Brylla E, Tscheudschilsuren G, Santos AN, Nieber K, Spanel-Borowski K, Aust G. Differences between retinal and choroidal microvascular endothelial cells (MVECs) under normal and hypoxic conditions. Exp Eye Res 2003; 77: 527-535, doi: 10.1016/S0014-4835(03)00219-7.

26. Tscheudschilsuren G, Aust G, Nieber K, Schilling N, SpanelBorowski K. Microvascular endothelial cells differ in basal 
and hypoxia-regulated expression of angiogenic factors and their receptors. Microvasc Res 2002; 63: 243-251, doi: 10.1006/mvre.2001.2346.

27. Hallgren J, Gurish MF. Pathways of murine mast cell development and trafficking: tracking the roots and routes of the mast cell. Immunol Rev 2007; 217: 8-18, doi: 10.1111/ j.1600-065X.2007.00502.x.

28. Miller HR, Pemberton AD. Tissue-specific expression of mast cell granule serine proteinases and their role in inflammation in the lung and gut. Immunology 2002; 105: 375-390, doi: 10.1046/j.1365-2567.2002.01375.x.

29. Caughey $\mathrm{GH}$. Mast cell tryptases and chymases in inflammation and host defense. Immunol Rev 2007; 217: 141-154, doi: 10.1111/j.1600-065X.2007.00509.x.

30. Schwartz LB. Tryptase from human mast cells: biochemistry, biology and clinical utility. Monogr Allergy 1990; 27: 90-113.
31. Lagunoff $D$, Pritzl $P$. Characterization of rat mast cell granule proteins. Arch Biochem Biophys 1976; 173: 554-563, doi: 10.1016/0003-9861(76)90292-7.

32. Stack MS, Johnson DA. Human mast cell tryptase activates single-chain urinary-type plasminogen activator (pro-urokinase). J Biol Chem 1994; 269: 9416-9419.

33. Muramatsu M, Katada J, Hattori M, Hayashi I, Majima M Chymase mediates mast cell-induced angiogenesis in hamster sponge granulomas. Eur J Pharmacol 2000; 402 181-191, doi: 10.1016/S0014-2999(00)00350-2.

34. Metsarinne KP, Vehmaan-Kreula $P$, Kovanen PT, Saijonmaa O, Baumann M, Wang Y, et al. Activated mast cells increase the level of endothelin-1 mRNA in cocultured endothelial cells and degrade the secreted peptide. Arterioscler Thromb Vasc Biol 2002; 22: 268-273, doi 10.1161/hq0202.103994. 